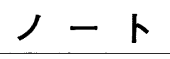

\title{
高速液体クロマトグラフィーによるディーゼル排気微粒 子中の多環芳香族炭化水素の定量
}

\author{
新 井 実* \\ (1993 年 6 月 10 日受理)
}

\author{
1 緒言
}

ディーゼルエンジンより排出される微粒子中のタール 状成分である SOF (soluble organic fraction) の中に含 まれる多環芳香族炭化水素 $\mathrm{PAH}$ は種々の物質に含まれ る注目すべき物質と言われる．PAH の源は主として然 料であるので1), SOF 中の PAH の存在量は燃料中の芳 香族炭化水素の影響を強く受けると考えられる. SOF 中の PAH が燃料の性状によって受ける影響を知ること はSOF の低減対策と同時に SOF の生体影響的な問題 として重要なことであるが, 研究例の中では, まだ十分 明確にされていない.

PAH の分析手法としての研究例は HPLC が一般であ る2) -5). その他には HPLC とキャピラリー GC をオン ライン化したシステムによる軽油中の PAH の分析 ${ }^{1)}$, 水素炎イオン化検出器（FID）を用いたキャピラリー GC や GC-MS, HPLC を用いて二トロ PAH の量とサ ンプリング時間との関係を調査した例 ${ }^{6)}$, FID 検出器を 用いたキャピラリー GC や， GC-MS によって PAH の 同定を行った例7), そして多成分の分離能に優れる FT-IR GC と組み合わせた GC-FTIRによって環境 試料中の $\mathrm{PAH}$, ニトロ $\mathrm{PAH}$ を分離, 同定した例があ $る^{8)}$. 本報と同様に HPLC を用いている研究例では, 機関運転条件による PAH 排出特性についての研究2)31 や, PAH 検出に UV 検出器を用いた例 ${ }^{4}$ がある. 又, これらの研究例では蛍光検出器使用時の蛍光プログラム を単一としているが203)5), 本報文では, 蛍光プログラム を 2 種とした蛍光検出器を使用し, 各々のプログラム において試料の注人を行った. 更に多種の $\mathrm{PAH}$ の分離 を行うため,こう配溶離法を用い, 研究例では明確にな っていない部分である, 燃料による $\mathrm{PAH}$ 排出特性を明 らかにした. その結果, PAHに対し選択的に高感度を

* (株)いす ゙佒研究所：252 神奈川県藤沢市土棚 8
有する蛍光検出器の特性に加え, 蛍光プログラムの選択 により多種の $\mathrm{PAH}$ を良好に分離識別することが可能と なった。

\section{2 実験}

\section{$2 \cdot 1$ 標準物質, 使用燃料}

検量線の作成のために, 米国 NIST が供給している 標準物質 SRM 1647 を使用した。この標準物質は米国 EPAによって重要とされている 16 種の $\mathrm{PAH}$ の混合物 で,アセトニトリルに溶解されている.この溶液中の各 PAH の濃度は Table 1 の様になっている. 又, 排気微 粒子を採取する際の使用燃料は軽油セタン価を 3 種 $(42,47,57)$ に変化させた硫黄分 $0.05 \mathrm{wt} \%$ の低硫黄軽 油を用いた。 それぞれのセタン価に対応するアロマ分 (芳香族炭化水素) は $38,33,24 \%$ であり, 低セタン価 ほど, 高アロマ含有の然料である.

Table 1 Standard material SRM 1647 supplied by NIST

\begin{tabular}{lc}
\hline \multicolumn{1}{c}{ PAH } & Concentration/mg $\mathrm{m}^{-1}$ \\
\hline Naphthalene & $22.5 \pm 0.2$ \\
Acenaphthylene & $19.1 \pm 0.2$ \\
Acenaphthene & $21.0 \pm 0.4$ \\
Fluorene & $4.92 \pm 0.1$ \\
Phenanthrene & $5.06 \pm 0.1$ \\
Anthracene & $3.29 \pm 0.1$ \\
Fluoranthene & $10.1 \pm 0.2$ \\
Pyrene & $9.84 \pm 0.1$ \\
Benz $[a]$ anthracene & $5.03 \pm 0.1$ \\
Chrysene & $4.68 \pm 0.1$ \\
Benzo $[b]$ fluoranthene & $5.11 \pm 0.1$ \\
Benzo $[k]$ fluoranthene & $5.02 \pm 0.1$ \\
Benzo $[a]$ pyrene & $5.30 \pm 0.1$ \\
Dibenz $[a, h]$ anthracene & $3.68 \pm 0.1$ \\
Benzo $[g, h, i]$ perylene & $4.01 \pm 0.1$ \\
Indeno $[1,2,3$-cd $]$ pyrene & $4.06 \pm 0.1$ \\
\hline
\end{tabular}




\section{$2 \cdot 2$ 装 置}

使用した HPLC 装置仕様や条件を Table 2 に示す. 検出器は対象とする PAH に対し, 高感度である蛍光検 出器を用い, 更に多種の $\mathrm{PAH}$ の検出感度と分離をよく するため, 蛍光プログラムを 2 種使用した. 固定相に は化学結合型シリカの ODS カラム, 移動相には水, ア セトニトリルを用いる逆相, 分配クロマトグラフィーと し，溶媒組成を時間で変化させるこう配溶離法を用い た. PAH は非常に多くの炭化水素の混合物であるの で, ピークの広がりや感度の低下を防ぐのが狙いであ る. 移動相プログラムを Table 3 に示す.

\section{$2 \cdot 3$ 試料採取方法}

排気ガス測定車両は排気量 2.81 の直接噴射式ディ一 ゼル機関を搭載した車両を使用した．使用燃料を交換し ながら，車両走行装置を使用して米国排気規制用テスト モードを走行し，試験車両の排気ガスを排気希釈トンネ ルに導入した。希釈された排気ガスを Pallflex 製テフロ ンコーティンググラスファイバーフィルター（型式 TX40H120WW, 直径 $47 \mathrm{~mm}$ ) に通し, 排気微粒子を捕 集した。

Table 2 HPLC specifications and conditions

\begin{tabular}{ll}
\hline \multicolumn{1}{c}{ Item } & \multicolumn{1}{c}{ Specification and condition } \\
\hline $\begin{array}{l}\text { System controller and } \\
\text { pump }\end{array}$ & Waters' 600E \\
$\begin{array}{l}\text { Column heater } \\
\text { Fluorescence detector }\end{array}$ & Waters' TCM \\
$\begin{array}{l}\text { Auto injector } \\
\text { Column }\end{array}$ & Waters' 470 \\
& Chrom Spher PAH (ODS) \\
Colum temperature & $100 \times 3.00 \mathrm{~mm}$ \\
Eluent \& liquid phase & $35^{\circ} \mathrm{C}$ \\
$\quad$ program & refer to Table 3 \\
Flow rate & $1 \mathrm{ml} \mathrm{min}{ }^{-1}$ \\
Pump pressure & $27.6 \mathrm{MPa}$ \\
\hline
\end{tabular}

\section{$2 \cdot 4$ 試料前処理}

排気微粒子を捕集したフィルターをソックスレ一抽出 器を用い, SOFを抽出する. パティキュレート中の SOF の抽出については溶媒としてトルエン, ジクロロ メタンなどが用いられているが，本論文においてはトル エンを使用したＳSOF の抽出量と抽出時間との関係を みた結果において，6 時間以上では抽出量に増大はな く，ほぼ一定の値となったことから抽出は 6 時間で十 分であり，又抽出再現性にも問題ない時間と考えられ た。溶媒の種類を変えた場合のSOF 抽出量にはほぼ相 違がない4ことから抽出率については值は求められない ものの，上限であると考えられる（サンプル中の SOF の含有量を求める基準は他にないため) そして, HPLC への試料導入までに更にジクロロメタン,メタノールに よる分画を行った.これらの手順については次のように 行った．分画の例については，必ずしも研究例に述べら れてはいないが，文献調査の中で見られた例67)では， 本論文とほぼ同様な操作を行っている.

[試料前処理手順]

ソックスレー抽出器で 6 時間, トルエン (HPLC グ レード） $185 \mathrm{ml}$ で抽出した. 抽出サイクルは 30 分であ った。ロータリーエバポレーターで溶剤蒸発させ（水温 $60^{\circ} \mathrm{C}, \mathrm{SOF}$ は高沸点炭化水素の混合物であるので損失 はない)，0.5 ml に濃縮した．次いでジクロロメタン 20 $\mathrm{ml}$ を加え, $40^{\circ} \mathrm{C}$ で更に溶郕蒸発を行い, $1 \mathrm{ml}$ まで濃 縮した。得られた抽出物を $2 \mathrm{ml}$ 容量のシリンジに移 し, Waters' SEP-PAK シリカカートリッジに注入し た. $1 \mathrm{ml}$ のジクロロメタンで 5 回, 抽出物の入ってい たフラスコを洗い, この溶液も洗浄ごとにシリンジから カートリッジに注入した. 抽出物のトルエン, ジクロロ メタン混合溶液とフラスコ洗浄液のカートリッジ通過液 を $0.5 \mathrm{ml}$ まで溶剤蒸発させた. メ夕ノール（HPLCグ レード） $10 〜 20 \mathrm{ml}$ を加え， $50^{\circ} \mathrm{C}$ で $1 \mathrm{ml}$ まで溶剤蒸発 させた. $2 \mathrm{ml}$ 容量のシリンジを用い, メ夕ノール抽出 物を $0.45 \mu \mathrm{m}$ の孔径のフィルターで沪した. 抽出物を フィルターを介し， $10 \mathrm{ml}$ メスシリンダーに移し, $1 \mathrm{ml}$ のメタノールで 2 回, 抽出物の入っていたフラスコを

Table 3 Liquid phase program

\begin{tabular}{lcccc}
\hline Time & Flow rate/ & Liquid phase A, & Liquid phase B, & \multicolumn{2}{c}{ Liquid phase C, } \\
$\mathrm{cm}^{3} \mathrm{~min}^{-1}$ & $\mathrm{CH}_{3} \mathrm{CN} / \mathrm{H}_{2} \mathrm{O}=50 / 50$ & $0 \%$ & $15 \%$ \\
\hline Start & 1.0 & $85 \%$ & $100 \%$ & $0 \%$ \\
43 min & 1.0 & $0 \%$ & $100 \%$ & $0 \%$ \\
$44 \mathrm{~min}$ & 1.5 & $0 \%$ & 0 & $0 \%$ \\
\hline
\end{tabular}


Table 4 Retention time, condition and program of fluorescence

\begin{tabular}{|c|c|c|c|c|}
\hline PAH & $t_{\mathrm{r}} / \min ^{\dagger}$ & $\lambda_{\mathrm{ex}} / \mathrm{nm}$ & $\lambda_{\mathrm{em}} / \mathrm{nm}$ & Program No. \\
\hline Pyrene & 23.6 & 286 & 433 & I \\
\hline Fluoranthene & 22.3 & 266 & 402 & II \\
\hline Benz $[a]$ anthracene & 31.3 & 266 & 402 & I \\
\hline Chrysene & 31.7 & 266 & 402 & I \\
\hline Benzo $[b]$ fluoranthene & 35.4 & 294 & 430 & I \\
\hline Benzo $[k]$ fluoranthene & 36.6 & 294 & 430 & I \\
\hline Benzo $[a]$ pyrene & 37.6 & 294 & 430 & I \\
\hline Dibenz $[a, h]$ anthracene & 39.0 & 294 & 430 & II \\
\hline Benz $[g, h, i]$ perylene & 39.6 & 294 & 430 & II \\
\hline Indeno $[1,2,3-\mathrm{cd}]$ pyrene & 41.4 & 294 & 482 & $\mathrm{I}$ \\
\hline
\end{tabular}

$\dagger$ Retention time by standard material. Refer to Table 5 for programs I \& II.

洗い,この溶液をフィルターを介し, $10 \mathrm{ml}$ メスシリン ダーに移した。得られたサンプルボリュームを記録し， サンプルは暗所に保管した。

\section{$2 \cdot 5$ 検量線の作成}

$2 \cdot 1$ で述べた標準物質をアセトニトリルで $12.5 \%$ 容 積濃度に希釈した溶液を $1 \mu \mathrm{l}$ 使用し, 検量線の作成を 行った.この希釈溶液は変質を防ぐため, 光を避けて保 管した。検量線の作成の際, fluoranthene, pyrene, chrysene, benz $[a]$ anthracene, benz $[a]$ pyrene について検 出下限, 直線性, 相関係数を求めた. 検出下限について は, $0.24 \sim 0.91 \mu \mathrm{g} / 1$ であった. 直線性は $500 \mu \mathrm{g} / 1$ まで 確認され, 相関係数は $0.998 \sim 1.003$ であった.

\section{3 結果及び考察}

\section{$3 ・ 1$ 蛍光プログラム, 溶媒組成の検討と標準物質に よる保持時間の決定}

PAH の定量に先立ち, 各対象標準物質による保持時 間の決定を行った. 結果を Table 4 に示す. 2 種の蛍光

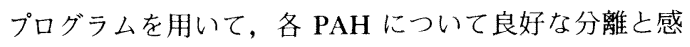
度を有する蛍光プログラムを使用することとした．この プログラムは検出感度向上を得ることを目的として各々 のPAHに適した励起，蛍光波長を使用した. 対象とし

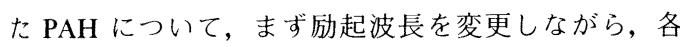
PAH の励起状況をみて最適波長範囲を決定した，次に 蛍光波長を変化させ, 同様に各 $\mathrm{PAH}$ の蛍光状況から最 適波長範囲を決定した. そして, 保持時間の短い物質順 に並べた結果とこれらの励起, 蛍光波長の最適範井から 励起, 蛍光波長の共通化の可能な物質についてグループ 化を行い, 同一の励起, 蛍光波長を使用した. 従って, 各対象標準物質の保持時間もこれら 2 種の蛍光プログ
Table 5 Fluorescence program

\begin{tabular}{ccccc}
\hline & Time/min & $\lambda_{\text {ex }} / \mathrm{nm}$ & $\lambda_{\text {em }} / \mathrm{nm}$ \\
\hline (I) Start & 0 & 286 & 433 \\
Step 1 & 26 & 266 & 402 \\
Step 2 & 33 & 294 & 430 \\
Step 3 & 39.4 & 294 & 482 \\
(II) Start & 0 & 266 & 402 \\
Step 1 & 32.5 & 294 & 430 \\
\hline
\end{tabular}

ラムにおいて求めた．これら蛍光プログラムを I, II と したとき, 各 PAH の定量がいずれのプログラムで実施 されたかは Table 4 の中に示す. 蛍光プログラム I, II の内容を Table 5 に示す. 蛍光プログラム I, II の使い 分けにより，Iにおいてはほとんど検出感度の得られな かった pyrene, dibenz $[a, h]$ anthracene, benz $[g, h, i]$ perylene がIIにより感度の向上が得られた。なお，注入は蛍光 プログラム I, II の各々 1 回ずつ必要である. 又, 溶媒 組成の選択としては, PAHのような極性の小さな物質 に対する液相として用いられ，研究例にも多く使用され ているアセトニトリルを使用したが，これに水とのグラ ディエントを用いてアセトニトリルの比率を変化させ, 各 $\mathrm{PAH}$ を溶離させた。

\section{$3 \cdot 2$ PAH クロマトグラム}

蛍光プログラムIにおける標準物質の注入結果は Fig. 1 から明らかなとおり, benz $[a]$ anthracene, chrysene のバンドは近接しているため, 分析結果にお ける両物質の分離を検討した. 燃料 3 種類に対し, 排 気後処理として触媒使用有無の条件 2 種類の組み合わ せの合計 6 条件における 6 サンプルの分離度, 分離係 


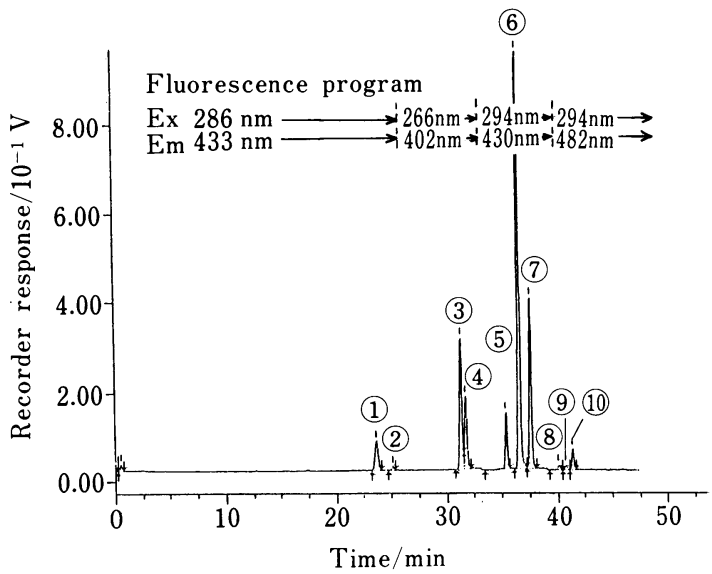

Fig. 1 Chromatogram of PAH standard material under the condition of fluorescence program I

Peaks identification (retention time \& eluted substance): (1) 23.60 fluoranthene, (2) 25.07 pyrene, (3) 31.28 benz $[a]$ anthracene, (4) 31.69 chrysene, (5) 35.42 benz $[b]$ fluoranthene, (6) 36.61 benzo $[k]$ fluoranthene, (7) 37.63 benzo $[a]$ pyrene, (8) 40.10 dibenz $[a, h]$ anthracene, (9) 40.72 benzo $[g, h, i]$ perylene, (10) 41.36 indeno $[1,2,3$-cd $]$ pyrene

数, 理論段数, 実効理論段数はそれぞれ Table 6 のよ うであった。これらの両物質の分離は分離度, 分離係数 からみると分離が不完全であるが，クロマトグラム上の ピークの尖鋭さは確保されており，定量上での大きな問 題はない. 又他の分析対象物質についての分離は分析例 のように良好である. 蛍光プログラム II における分析 対象物質は pyrene, dibenz $[a, h]$ anthracene, benz $[g, h, i]$ perylene であり, 蛍光プログラムIにおいてはいずれ も検出感度が低かったが，Fig. 2 に示すとおり，いずれ の物質においても分離，検出感度は良好である，又，

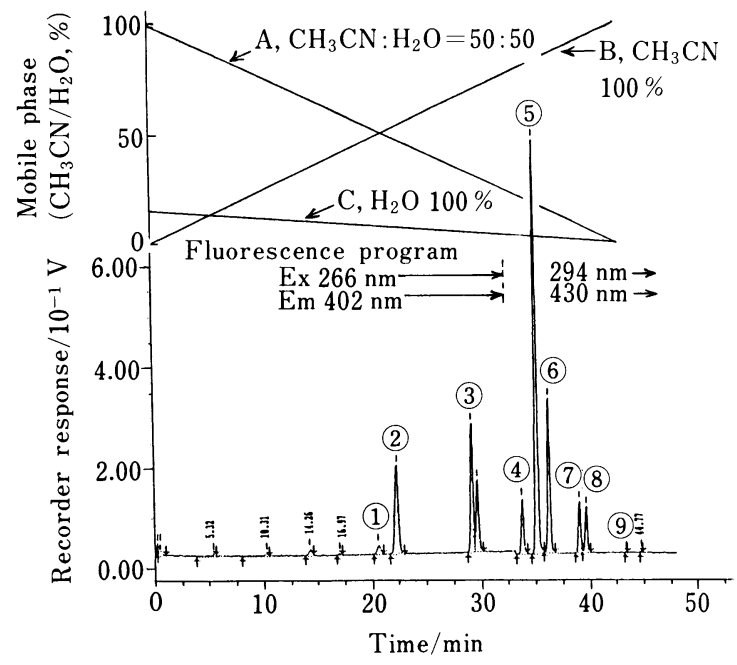

Fig. 2 Chromatogram of PAH standard material under the condition of fluorescence program II and gradient eluent program (gradient eluent program is common for programs I and II)

Peaks identification: (1) 20.59 fluoranthene, (2) 22.27 pyrene, (3) 29.18 benz $[a]$ anthracene, (4) 33.76 benz[b] fluoranthene, (5) 35.10 benzo $[k]$ fluoranthene, (6) 36.22 benzo $[a]$ pyrene, (7) 39.02 dibenz $[a, h]$ anthracene, (8) 39.64 benzo $[g, h, i]$ perylene, (9) 43.32 indeno $[1,2,3-\mathrm{cd}]$ pyrene

Table 3 にその内容を示す移動相プログラムについて は, 移動相が完全にアセトニトリル $100 \%$ に変わる 43 $\min$ からの第 2 ステップ前に, 分析対象物質の中で一 番保持時間の長い indeno[1,2,3-cd] pyrene でも検出が終 わっており，(蛍光プログラムI）結果的には開始より $43 \mathrm{~min}$ までの第一のステップで分離, 検出が終わって いる.

Table 6 Resolution and number of theoretical plates about benz $[a]$ anthracene and chrysene

\begin{tabular}{|c|c|c|c|c|c|c|}
\hline \multirow{2}{*}{$\begin{array}{c}\text { Fuel } \\
\text { Catalyst }\end{array}$} & \multicolumn{2}{|c|}{ Cetane 42} & \multicolumn{2}{|c|}{ Cetane 47} & \multicolumn{2}{|c|}{ Cetane 57} \\
\hline & Yes & No & Yes & No & Yes & No \\
\hline Resolution $R_{\mathrm{s}}$ & 0.883 & 0.775 & 0.684 & 0.790 & 1.034 & 0.700 \\
\hline Separation factor $\alpha$ & 1.02 & 1.01 & 1.02 & 1.01 & 1.01 & 1.01 \\
\hline \multicolumn{7}{|l|}{ Number of theoretical plates $N\left(\times 10^{4}\right)$} \\
\hline Benz $[a]$ anthracene & 4.0 & 4.0 & 3.6 & 2.6 & 12.0 & 4.0 \\
\hline Chrysene & 6.2 & 4.1 & 7.1 & 6.2 & 6.3 & 5.6 \\
\hline \multicolumn{7}{|l|}{ Number of effective plates $N_{\text {eff }}\left(\times 10^{4}\right)$} \\
\hline Benz $[a]$ anthracene & 3.8 & 3.8 & 3.4 & 2.5 & 11.0 & 3.8 \\
\hline Chrysene & 5.9 & 3.9 & 6.8 & 5.9 & 6.0 & 5.4 \\
\hline
\end{tabular}


Table 7 Effect of fuel specification on PAH in SOF $(\mu \mathrm{g} / \mathrm{g})$

\begin{tabular}{|c|c|c|c|c|c|c|}
\hline \multirow{2}{*}{$\begin{array}{c}\text { Fuel cetane number } \\
\text { Catalyst }\end{array}$} & \multicolumn{2}{|c|}{42} & \multicolumn{2}{|c|}{47} & \multicolumn{2}{|c|}{57} \\
\hline & No & Yes & No & Yes & No & Yes \\
\hline Fluoranthene & 68.40 & 41.40 & 52.40 & 37.40 & 51.00 & 25.90 \\
\hline Pyrene & 85.70 & 50.90 & 60.40 & 47.60 & 64.40 & 45.00 \\
\hline Benz $[a]$ anthracene & 10.20 & 4.94 & 4.08 & 5.23 & 4.39 & 5.37 \\
\hline Chrysene & 24.40 & 9.45 & 11.00 & 7.53 & 6.81 & 7.61 \\
\hline Benzo $[b]$ fluoranthene & 5.70 & 6.48 & 4.42 & 6.80 & 4.47 & 6.79 \\
\hline Benzo $[k]$ fluoranthene & 2.02 & 2.42 & 6.02 & 2.79 & 1.47 & 3.11 \\
\hline Benzo $[a]$ pyrene & 5.33 & 6.80 & 4.16 & 7.64 & 4.16 & 7.63 \\
\hline Dibenz $[a, h]$ anthracene & 0.65 & 0.92 & 0.57 & 0.97 & 0.43 & 2.04 \\
\hline Benz $[g, h, i]$ perylene & 5.39 & 9.76 & 4.44 & 10.80 & 3.76 & 11.70 \\
\hline Indeno $[1,2,3$-cd $]$ pyrene & 2.65 & 5.21 & 1.98 & 5.38 & N.D. & 4.56 \\
\hline Total PAH $(\mu \mathrm{g} / \mathrm{g})$ & 210.44 & 138.28 & 147.49 & 132.14 & 140.89 & 119.71 \\
\hline
\end{tabular}

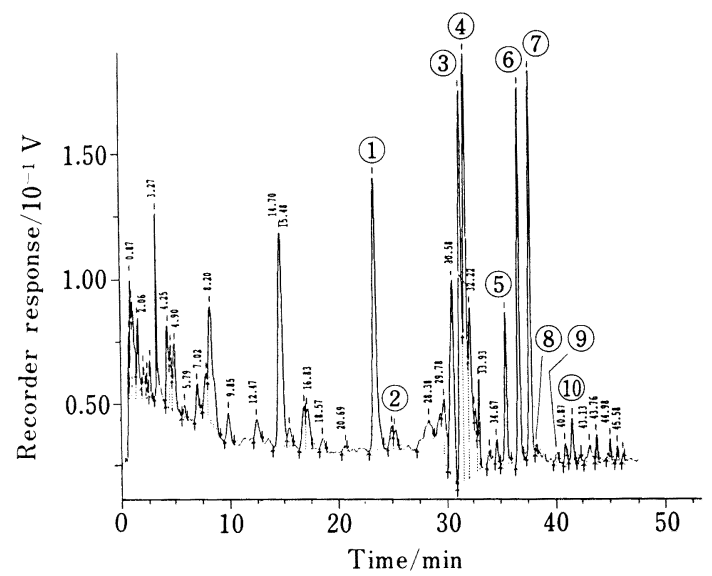

Fig. 3 Chromatogram of PAH sample under the condition of fluorescence program I (fuel cetane number 42 , with catalyst)

Peaks identification: (1) 23.43 fluoranthene, (2) 24.92 pyrene, (3) 31.36 benz $[a]$ anthracene, (4) 31.78 chrysene, (5) 35.50 benz [b] fluoranthene, (6) 36.73 benzo $[k]$ fluoranthene, (7) 37.76 benzo $[a]$ pyrene, (8) 38.28 dibenz $[a, h]$ anthracene, (9) 40.11 benzo $[g, h, i]$ perylene, (10) 41.35 indeno $[1,2,3-\mathrm{cd}]$ pyrene

\section{$3 \cdot 3$ 燃料及び排気浄化用触媒による PAH 検出値の} 变化

3 種類の燃料を使用した試験での排気微粒子より抽出 されたSOF を前処理した後, この溶液 $10 \mu \mathrm{l}$ を用いて 定量し，PAHについて Table 7 の結果を得た. 然料の 七夕ン価による $\mathrm{PAH}$ 排出值への影響は Benzo $[b]$ fluoranthene 以上の濃度のPAHに現れてお り, 七夕ン価の低い燃料において PAH が増大する傾向

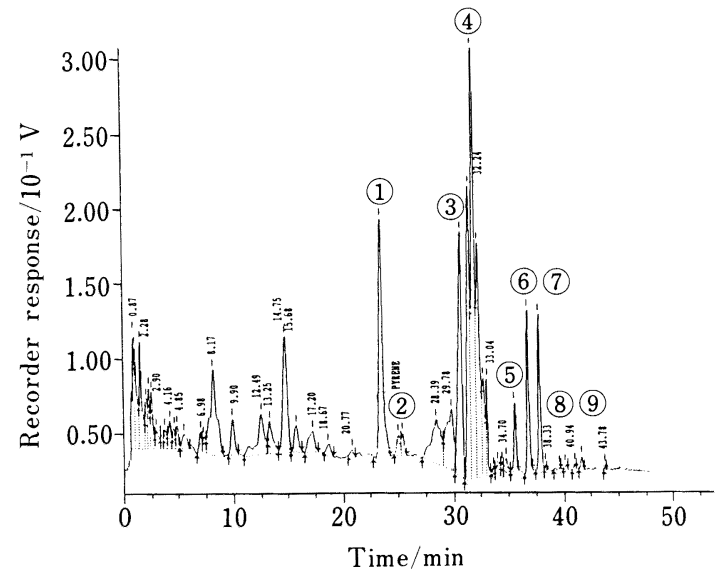

Fig. 4 Chromatogram of PAH sample under the condition of fluorescence program I (fuel cetane number 42, without catalyst)

Peaks identification: (1) 23.44 fluoranthene, (2) 25.07 pyrene, (3) 31.48 benz $[a]$ anthracene, (4) 31.84 chrysene, (5) 35.55 benz $[b]$ fluoranthene, (6) 36.78 benzo $[k]$ fluoranthene, (7) 37.80 benzo $[a]$ pyrene, (8) 40.12 benzo $[g, h, i]$ perylene, (9) 41.58 indeno $[1,2,3$-cd $]$ pyrene

が認められる.ただし，これ以下の排出値のPAH では 傾向をつかむのは難しい. Fig. 3, Fig. 4 にそれぞれ然 料セタン価 42 使用時の蛍光プログラムIにおける白金 を主体とした触媒使用時, 未使用時の PAH クロマトグ ラムを示す。 又, 同様に Fig. 5, Fig. 6 にそれぞれ然料 セ夕ン価 42 使用時の蛍光プログラムII における触媒 使用時, 未使用時の $\mathrm{PAH}$ クロマトグラムを示す。これ らのクロマトグラムから chrysene 以前の保持時間で得 


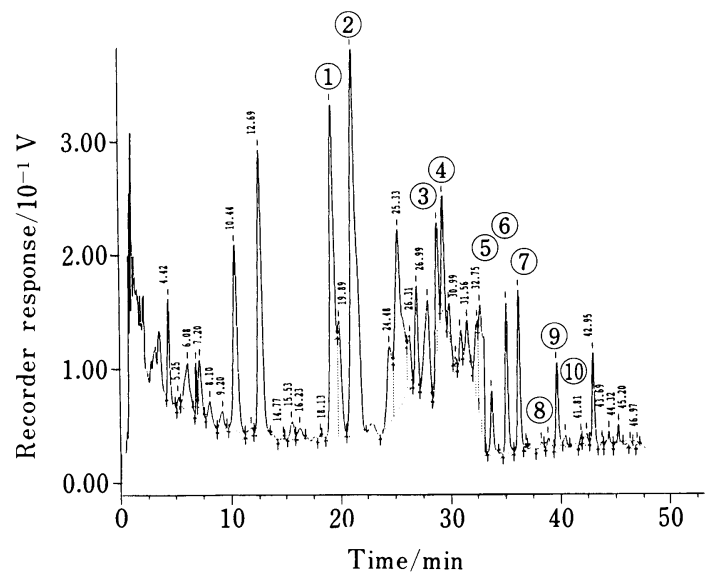

Fig. 5 Chromatogram of PAH sample under the condition of fluorescence program II (fuel cetane number 42 , with catalyst)

Peaks identification: (1) 19.33 fluoranthene, (2) 21.23 pyrene, (3) 28.90 benz $[a]$ anthracene, (4) 29.43 chrysene, (5) 33.76 benzo[b] fluoranthene, (6) 35.13 benzo $[k]$ fluoranthene, (7) 36.26 benzo $[a]$ pyrene, (8) 38.94 dibenz $[a, h]$ anthracene, (9) 39.73 benzo$[g, h, i]$ perylene, (10) 40.41 indeno $[1,2,3-\mathrm{cd}]$ pyrene

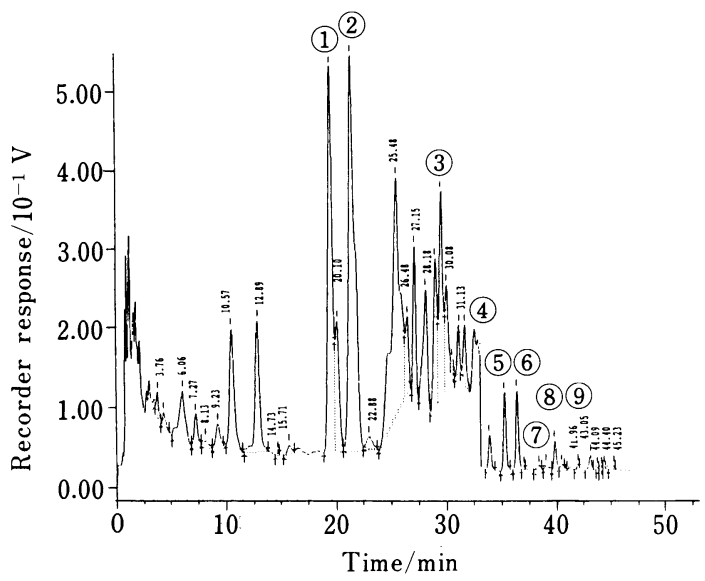

Fig. 6 Chromatogram of PAH sample under the condition of fluorescence program II (fuel cetane number 42 , without catalyst)

Peaks identification: (1) 19.53 fluoranthene, (2) 21.43 pyrene, (3) 29.59 chrysene, (4) 33.88 benzo[b]fluoranthene, (5) 35.27 benzo $[k]$ fluoranthene, (6) 36.39 benzo $[a]$ pyrene, (7) 39.03 dibenz $[a, h]$ anthracene, (8) 39.84 benzo $[g, h, i]$ perylene, (9) 40.48 indeno $[1,2,3$-cd $]$ pyrene
られる PAH の検出值は触媒の使用により，大きく減少 しているのが分かる. Table 7 に各 PAH の検出值を示 す. 全 PAH の值でみると, 七夕ン価 42 の燃料使用時 の触媒での低減が最も大きく, 触媒使用時においてはセ タン価 47, 57 の然料との差は $20 \%$ 以下に減少してい る. その他, 触媒を使用することによって $\mathrm{PAH}$ が増加 しているデータがあるが，これらは検出值の絶対值が小 さいための誤差もあると考えられるとともに，触媒を使 用した場合，触媒活性温度以下の低排気温時には触媒表 面への吸着があるため飽和時や温度上昇に伴う脱離によ って分析値が増加したことも考えられる.

以上，排気微粒子より抽出された SOF 中に含まれる $\mathrm{PAH}$ の定量を高速液体クロマトグラフィーにより行っ た。その結果，(1) 排気微粒子より抽出した SOF 試料 をシリカカートリッジを使用し，分画することによって 試料からの $\mathrm{PAH}$ を分離可能であった。（2）こう配溶離 法を用いた移動相と, 固定相に ODS カラムを用いた逆 相分配クロマトグラフィーに，蛍光プログラム 2 種を 用いた蛍光検出器を使用し，多種の $\mathrm{PAH}$ を分離した結 果, benz $[a]$ anthracene, chrysene 付近の一部の PAH に ついては, 分離度, 分離係数のうえでは不完全な分離で あったが，定量は可能であった。（3）移動相プログラム についてはアセトニトリル/水, 水の段階がほぼ終了 し，アセトニトリル $100 \%$ になる直前までで対象物質 の全 PAH が良好に分離された，更に高分子量の PAH まで対象とした場合にはアセトニトリル $100 \%$ の液相 の段階が有効となると考えられる. (4) 蛍光プログラム を 2 種使用することで，一方のプログラムでは検出感 度の低い対象物質について, 改善され, 定量が可能であ った.（5）SOF 中に含まれる PAH に対して, 燃料, 白 金を主成分とした排気浄化用触媒の影響を調査した結 果, 燃料の芳香族炭化水素類は PAH の排出に影響し, 又, 触媒はこの影響を減少させることが明らかになっ た.

\section{文献}

1) I. L. Davies, K. D. Bartle, G. E. Andrews, P. T. Williams: J. Chromatogr. Sci., 26, 125 (1988).

2) D. Schuetzle, T. L. Riley, T. J. Prater, T. M. Harvey, D. F. Hunt: Anal. Chem., 54, 265 (1982).

3）泉川碩雄, 伊瀬洋昭, 菅 邦子, 福岡三郎, 舟島正 直, 横田久司, 中村 健, 梅原秀夫: 東京都環境科 学研究所年報, p. 3 (1990).

4）鈴木政之, 河合昭宏, 秋山賢一, 佐々木左宇介, 河 合サチ子, 坂入恵子, 末吉靖夫, 渡辺末男, 加地浩 成：(財)日本自動車研究所昭和 63 年度自工会受 
託研究報告書 (1989).

5) P. R. Shore, J. M. Tesh, J. Bootman: Society of Automotive Engineers, Technical Paper Series 870627 (1987).

6) A. Hartung, J. Kraft, J. Schulze, H. Kiess, K. H.
Lies: Chromatographia., 19, 269 (1984).

7) J. Schulze, A. Hartung, H. Kiess, J. Kraft, K. H. Lies: Chromatographia., 19, 391 (1984).

8) V. F. Kalasinsky, G. Saiwan, K. G. Whitehead: J. Chromatogr. Sci., 26, 584 (1988).

$\hat{s}$

Determination of polycyclic aromatic hydrocarbons in diesel particulates by high performance liquid chromatography. Minoru ARAI (Isuzu Advanced Research Engineering Center, Ltd., 8, Tsuchidana, Fujisawa-shi, Kanagawa 252)

High performance liquid chromatography was applied to the separation and determination of polycyclic aromatic hydrocarbons (PAH) extracted from diesel particulates. Soluble organic fraction (SOF) contained in PAH was obtained by Soxhlet extraction of particulate samples on filters. PAH were selectively separated from SOF samples, by a silica cartridge with solvents and they were then used for HPLC analyses. Each PAH was separated and quantified by using the methods of reversed phase and partition chromatography with gradient elution. Fluorescence detection with variable excitation and fluorescence wavelength was applied to detect many kinds of PAH with detection limits from 0.24 to $0.91 \mu \mathrm{g} \mathrm{l}^{-1}$. It was found that aromatics in the fuel strongly affected the quantity of $\mathrm{PAH}$ in the SOF.

(Received June 10, 1993)

\section{Keyword phrases}

high performance liquid chromatography; reversed phase chromatography; polycyclic aromatic hydrocarbon; diesel; fluorescence detector. 